\title{
A Enfermidade Sob o Olhar da Criança Hospitalizada
}

\section{The Children's Sense of Illness in the Hospital}

\author{
Helena de Oliveira ${ }^{1}$
}

OLIVEIRA, H. The Children's Sense of Illness in the Hospital. Cad. Saúde Públ., Rio de Janeiro, 9 (3): 326-332, jul/sep, 1993.

In this study, we assume that illness has a meaning during childhood, and that children are capable of speaking about it. Our objective is to unveil their representations concerning disease, medical treatment, hospitalization, and health personnel. This study was carried out in three pediatric hospitals in the city of Rio de Janeiro during the month of July 1990. Fifteen hospitalized children from five to eleven years of age were interviewed and asked to talk about the questions described above. The methodological approach was qualitative, in accordance with Bardin (1977) and Minayo (1988).

In speaking about their illnesses, the children refer to medical practice, contemporary family arrangements, and themselves as players or subjects.

Key words: Hospitalization; Psychosocial Aspects; Pediatric Care; Child's Play

\section{INTRODUÇÃO}

Durante muitos séculos a criança foi considerada um "não ser": "sem movimento na alma, sem forma reconhecível no corpo" (Ariès, 1981), no máximo um adulto em miniatura. Como a infância, da forma como hoje a conhecemos, inexistia, era impossível que se concretizassem tanto o "amor materno" quanto a Pediatria.

Este sentimento de indiferença pelas crianças parece explicar os altos índices de mortalidade prevalentes até o século passado. Bastava que nascessem para que fossem enviadas para as casas das amas-de-leite mercenárias, onde sobreviviam menos de $20 \%$ dos lactentes (Badinter, 1985). Bastava que "chorassem demais ou muito pouco" para que fossem atiradas nos rios, emparedadas em muros, obrigadas a ingerir gesso misturado ao leite, queimadas, estranguladas, “abandonadas nas estradas para servirem de alimento aos animais, ou enterradas em alicerces de edificios ou pontes para reforçar as estruturas" (Orlandi, 1985).

\footnotetext{
${ }^{1}$ Faculdade de Medicina da Universidade de Nova Iguaçu. Avenida Abílio Augusto Távora 2134, Nova Iguaçu, Rio de Janeiro, 26260-000, Brasil.
}

A necessidade de mão-de-obra nas indústrias, com a Revolução Industrial, fez nascer a idéia de que o fortalecimento da nação viria do número e da força de seu povo: crianças-adultos de amanhã. A sobrevivência infantil começou a ser uma preocupação econômica, e é este o primeiro passo em direção ao reconhecimento da singularidade do tempo da infância. A partir de então, e de uma forma crescente, surgiram os vestuários e brinquedos infantis, as creches, as primeiras leis de proteção à infância (Mead \& Wolfenstein, 1955) e, também, o "amor materno". Este, como o conhecemos hoje, foi um sentimento criado pela necessidade econômica de proteger a vida das crianças dos efeitos nocivos do aleitamento mercenário.

Só então o nascimento da Pediatria tornou-se possível dentro da Medicina, percorrendo o mesmo caminho do nascimento da infância. De um sentimento inicial de indiferença, a criança passou a ser vista, progressivamente, como cada vez mais singular e peculiar em relação ao adulto: sua anatomia e fisiologia, assim como suas enfermidades e terapêutica (Entralgo, 1976).

No entanto, o relacionamento com a doença infantil, ou mesmo com a criança enferma, tem sido ainda mediado pela mãe-adulto, como se a 
criança, por si só, não fosse capaz de informar ao pediatra sobre seu estado. Sem negar a "relativa" dificuldade de comunicação e de consciência de ser e estar da criança, partimos do pressuposto de que existe uma dimensão vivencial da enfermidade na infância sobre a qual a criança doente é capaz de saber e de dizer. E essa vivência expressa não só sua própria individualidade, mas todo um complexo de forças e de consciência coletiva que é o próprio fundamento de sua constituição enquanto sujeito e indivíduo.

\section{MATERIAL E MÉTODOS}

Este trabalho representa a síntese de uma dissertação de mestrado apresentada em maio de 1991 à Coordenação de Pós-Graduação em Saúde da Criança do Instituto Fernandes Figueira.

O objetivo deste estudo foi o de conhecer as representações sociais da enfermidade, a partir da criança, sob o viés da hospitalização.

A metodologia do trabalho em questão constou de entrevistas realizadas com crianças hospitalizadas, desenhos feitos pelas mesmas crianças e relatos de observação por parte do pesquisador.

A interpretação do material foi feita de forma complementar (entrevista/desenho/observação) e teve como eixo fundamental o estabelecimento de uma relação de empatia com cada criança. Com esta forma de análise, procuramos indicar as relações de significação possíveis que, para cada uma das crianças, teriam a enfermidade, a hospitalização e aqueles que delas cuidam no local, mas sempre dentro de um contexto médico. Algo que significou, em outros termos, uma tentativa de ampliar a abordagem de saúde, de humanizá-la, trazendo para dentro da Medicina fatores psicológicos, sociológicos, antropológi$\cos$ e da própria História da Humanidade.

A população de estudo foi constituída por 15 crianças com idade entre 5 e 11 anos, internadas em três hospitais pediátricos públicos localizados na cidade do Rio de Janeiro, no período de 1 a 31 de julho de 1990.

O tempo de internação das crianças entrevistadas oscilou entre 2 e 45 dias, sendo que em $78 \%$ delas este tempo foi inferior a 5 dias.
As entrevistas foram semi-estruturadas, individuais, com duração média de 1 (uma) hora cada, em número de 2 para cada criança. Destas entrevistas constaram, além dos dados de identificação, questões pertinentes a um roteiro específico: o cotidiano antes da internação, a visão do hospital e a compreensão do "estar doente".

Os desenhos foram livres, numa primeira etapa, e dirigidos, numa segunda etapa, quando a criança era convidada a desenhar o hospital, a sua doença, o médico, sendo sempre estimulada a falar sobre eles.

A observação foi registrada no diário de campo e dela fizeram parte: a linguagem da criança, em suas várias modalidades de expressão (gestos, silêncios, lapsos, lágrimas, etc.); o ambiente no qual ocorreu a interação; e os sentimentos despertados no pesquisador durante a entrevista.

Após o término da coleta de dados foi feita uma análise de conteúdo, conforme recomendações de Minayo (1988) e Bardin (1977), que deu origem às grandes categorias discutidas $\mathrm{e}$ apresentadas a seguir.

\section{O MUNDO INFANTIL NA ENFERMIDADE}

\section{Os Hospitais}

"Estas casas comunais de doentes que funcionavam como substitutos da família, fazendo circular o mesmo olhar da compaixão (familiar)" (Foucault, 1980).

Falando de sua enfermidade, a criança doente nos conta da força e poder do saber médico como instrumento de destituição da subjetividade e de anulação da experiência do adoecer na reclusão hospitalar. Violência física dos procedimentos médicos, violência psicológica das relações inter-humanas, o espaço do hospital mostra-se como marca indelével de ruptura em todos os níveis de vida da criança. Rupturas inevitáveis, algumas; outras, criadas pela própria lógica de pensar a saúde e a doença e por esforços institucionais quase inaudíveis de reconstituir e religar a continuidade perdida.

As entrevistas nos mostram que os sintomas surgem na percepção da criança quando estes 
ocasionam dor ou quando modificam seu comportamento habitual: não andar, não fazer a redação, não aceitar um biscoito oferecido por um amigo. Não são codificados ainda como doença, a não ser pela mãe, que, por algum sinal visível na criança, indica que algo não vai bem: o pé está inchado, a criança desmaiou, teve uma convulsão. Mesmo assim, nem sempre a doença é um evento médico, pois o acesso é bastante difícil, levando os familiares a recorrerem, com freqüência, às rezas e às benzeduras: "Lá não tem hospital perto, aí eu fiquei em casa e minha tia rezou meu machucado" (J. Carlos, 11 anos). Ao se decidir pela hospitalização, procura-se um local com alguma referência familiar, o que nem sempre é conseguido. É comum a criança doente dar entradas sucessivas em vários hospitais, onde ora faltam medicamentos, ora exames laboratoriais, ora médicos, ora simplesmente leitos disponíveis.

Ultrapassados todos os obstáculos, relatados exaustivamente pela mídia para as populações de baixa renda, a criança finalmente consegue iniciar sua terapêutica hospitalar. Dentro do hospital, sua primeira impressão é de estranhamento: as escadas, as enfermarias, os medicamentos, os equipamentos, os procedimentos, as funções, as profissões e os nomes da equipe técnica. Há um profundo desconhecimento do ato médico como um todo. Este surge como algo vindo repentinamente de fora, fragmentado em intervenções invasivas, um ato cujo sentido a criança custa a encontrar na cura da doença, associando-o mais a intenções punitivas e a castigos. Há uma sensação de abandono, de que a função de cuidar não é desempenhada por qualquer das pessoas que a cercam. "Minha mãe vai vim", responde Susie, de 5 anos.

Somente nas hospitalizações prolongadas, por exemplo, no caso de doenças crônicas, é que ela consegue iniciar um conhecimento do nome de sua doença, do cotidiano hospitalar e dos profissionais que ali desempenham suas funções. Este conhecimento, no entanto, resulta muito mais de um esforço da criança do que de uma preocupação da equipe médica em lhe transmitir os acontecimentos, o que a rebaixa - como doente e como criança - à condição de objeto da enfermidade. Quando muito, fala-se com os pais. "Quem é que sabe do que tá acontecendo aqui com você?" Só os médicos e a minha mãe", responde Cláudio, de 9 anos.

O hospital é, para a criança, um local de proibições: não se pode andar pelos corredores, jogar bola, tomar ar fresco, falar alto, conversar com outras crianças, brincar. Mas, paradoxalmente, é um local de infantilização, onde crianças grandes são colocadas em berços e alimentadas através de mamadeiras - o que lhes causa profunda indignação. "Me botaram pra dormir no berço. Eu não queria" (Fred, 5 anos); "Aqui me dão suco na mamadeira. Eu não gosto. Eu tomo no copo" (Márcio, 6 anos).

É um local de solidão, de lágrimas e de saudade, onde a criança é separada de seus irmãos, de seu pai e, principalmente, de sua mãe, que é proibida de entrar e obrigada a deixar seu filho dormir ali, sozinho, ambos em prantos.

Talvez por tudo isso, o hospital é um local para o qual a criança nunca deseja ir, como nos conta Juliana, de 9 anos: "Meu medo era ter que ficar internada, pedi a Deus que não ficasse, mas fiquei".

Este evento de estar hospitalizada, os procedimentos médicos realizados e a própria doença surgem na percepção da criança como uma punição, um castigo, algo estreitamente relacionado a uma culpa subjacente: "Me machuquei porque fui brincar no escuro" (J. Carlos, 11 anos); "Fiquei de castigo, mas não é da minha mãe não, é do meu tio, por isso eu vim pra cá" (Cleiton, 5 anos). Às vezes, esta associação entre doença/hospitalização/culpa/castigo é bastante explícita, como nos relatos anteriores; outras vezes aparece de forma indireta, como, por exemplo, com Mauro e Luciana, que dizem, respectivamente: "Ali no quadro está a lista de quem vai ficar de castigo" e "Vim num carro de polícia pra cá".

Esta associação parece explicar mais além da objetividade dos fatos, porque os procedimentos médicos são vividos como suplícios: "Estou toda furada. Me furam muito aqui" (Susie, 5 anos); como verdadeiros rituais de tortura: "Tiraram um pedaço da minha veia" (Mauro, 7 anos); ou como podendo causar mutilações (apodrecer a carne, cortar o pé) ou, mesmo, ameaçar a própria sobrevivência: "Vou ser igual ao meu avô. Tirou um pedaço da veia, foi 
ficando velho, ficando velho, não agüentou... Pum. Morreu" (Mauro, 7 anos).

Mauro nos mostra, com o relato anterior, que as crianças se preocupam com a própria morte, mas só podem dizê-lo de forma indireta, pela magnitude da ameaça que o reconhecimento da própria finitude representa. Mas é de forma direta e cruel que falam da morte do outro, sem o cuidado com o impacto que isto causaria naquele que supostamente está mais próximo do fim. Rafael e Wallace desenham juntos. Wallace encontra-se no estágio terminal da Aids (ele morreu durante o trabalho de campo) e está muito deprimido. "Por que o Wallace está triste?", interroga o pesquisador. "Porque ele tá morrendo", responde Rafael, simplesmente.

Há uma dicotomia profunda entre o que a criança percebe como enfermidade, hospitalização e "cuidado" e o que a Medicina oferece como saúde, ato médico e tratamento.

João Carlos, com 29 dias de hospitalização, já sabe que aquilo que mais falta no hospital é o alimento da alma: "O que devia ter aqui prá criança? Alimento, médico pra conversar".

\section{A Família Nuclear: Condição de Existência da Criança Moderna}

"Fique certo de que há nesse amor (entre pais e filhos) uma força e uma bênção a que não se arrancará mesmo se for para muito longe..." (Rilke, 1983).

Falando de sua enfermidade, a criança doente nos conta sobre a forma de organização familiar da qual faz parte. Conta-nos da família nuclear — pai, mãe e filhos - e da importância que ainda subsiste para os tios e avós. Conta-nos dos diferentes papéis sociais atribuídos e vividos pelos membros da família em relação à criança, principalmente por homens e mulheres enquanto pais e mães.

No relato de sua enfermidade, a criança faz aparecer os tios, madrinhas e avós, que, mesmo residindo em casas diferentes, são alvo de muito carinho e de uma convivência estreita. As mulheres da família desempenham o papel de transmissoras da sabedoria popular, preparando chás, benzendo e rezando os machucados, substituindo, muitas vezes, a inexistência de médicos e hospitais acessíveis. Os irmãos são citados como semelhantes, ora no relato indireto da saudade e da solidão: "Se a minha irmã fica sozinha com meu tio ela ia chorar" (Carolina, 6 anos); ora na referência à doença e à morte: "Meu irmão morreu em casa. Ele não queria ir pro hospital" (Juliana, 9 anos).

Mas é a mãe o familiar mais próximo da criança doente, personificando o desempenho do "amor materno", da forma como o conhecemos hoje. É ela quem codifica os sintomas como sendo doença e, com a preocupação, o choro ou o desespero, comunica à criança uma medida de gravidade: "Minha mãe ficava nervosa" (Juliana, 9 anos); "Minha mãe ficava tão triste..." (Carolina, 6 anos). É ela quem cuida da criança quando esta fica doente, desde atitudes como "colocar no banheiro para cuspir" até "comprar remédios", "levar pra fazer exame" e "trazer pro hospital".

Este ponto de referência que as crianças colocam na mãe faz com que ela seja alvo de identificações amorosas muito profundas e primitivas, como nos contam Carolina (6 anos) e Susie (5 anos), respectivamente: "Quando a minha mãe chorava, eu chorava também"; "Quando eu tava na barriga dela, ela comia, eu comia; ela respirava, eu respirava também". E apesar de muitas vezes ser culpada pelo estado de enfermidade do filho - "A mãe dele não dava leite pra ele, só troço ruim, por isso ele tá doente" (Susie, 5 anos) - é dela que se sente muita saudade: "O que me deixa mais triste aqui? É quando a minha mãe vai embora" (Cláudio, 9 anos).

Seja porque houve um alargamento progressivo da função materna perante as crianças, como defendem alguns historiadores, seja porque a relação afetiva mais importante para todas as crianças tem sido sempre a materna, como defendem outros estudiosos, o pai aparece na assistência à criança doente quase sempre de forma indireta. Não é ele quem cuida, quem dá remédio, quem se desespera ou quem leva para o hospital. Antes, sua função é apoiar e incentivar as decisões maternas, funcionando como uma sombra viva, agindo sobre a criança através da mãe. "O médico queria me operar. Minha mãe não deixou e chamou meu pai" (Cláudio, 9 anos); "Aí meu pai falou assim, quando chegou de noite: leva essa menina no médico" (Luciana, 9 anos). 
Mas, na sombra deste pai distante surge um "novo pai", buscando compartilhar com as mulheres "o amor pelo filho e o sacrifício de si" - antes prerrogativas do amor materno. Alguns autores questionam se não é o "amor paterno" que está nascendo na história dos sentimentos, tão sensivelmente vivido por Carolina, do alto de seus 6 anos de idade:

"Meu pai mostra a língua pra mim (...) Papai conversa comigo, diz que é pra ficar dura, que não pode chorar, senão vai demorar mais (...) Meu pai faz um desenho tão bonito pra mim (...) Fico feliz quando vejo meu pai.”

\section{O Brincar}

"É através do jogo que começa o pensamento propriamente humano (...) É no jogo que contemplamos, que construímos (...) É pelo jogo que a humanidade se insinua por toda parte e é pelo jogo que essa humanidade se desenvolve" (Chateau, 1987).

Falando da enfermidade, a criança doente nos ensina - e precisamos aprender: brincar é uma forma de viver.

O não brincar é a marca da hospitalização: "A gente fica no hospital, não pode brincar", diz, em definitivo, David, de 7 anos. Esta é uma repressão feita pelas normas do hospital, muitas vezes justificadas pela necessidade de silêncio e de repouso para os pacientes internados. Mas as entrevistas sugerem que, para além das normas institucionais, o adulto não suporta qualquer manifestação do brincar, mesmo as mais simples. Conta-nos Mauro, de 7 anos: "Um dia eu tava agachado na cama, olhando pro menino, brincando com ele de carrinho, aí a tia chegou e gritou no meu ouvido, porque eu tava olhando ele e brincando com ele".

Este relato indica, além do desrespeito com que o adulto se dirige à criança, uma desvalorização da importância do brincar, tanto para quem "tava agachado na cama" quanto para o suposto alvo da brincadeira.

Apesar disso, as crianças sempre encontram uma maneira de brincar, mesmo quando não se trata de uma atividade promovida pelo local, como nas escolas: "Aqui no hospital? Ah, a gente brinca com as coisas aqui, né...", responde Mauro, de 7 anos.

Pelos desenhos, quando dispõem de lápis e papel, as crianças representam com riqueza suas experiências dentro do hospital. Dicotomia, fragmentação e longos espaços vazios predominam nas folhas de papel. Camas e seringas, balanças, divisórias e pias, sem médicos, sem enfermeiras, sem mães - falando do anonimato vivido dentro do espaço intra-hospitalar.

Mas, momento aguardado ansiosamente pelas crianças, o brincar é uma atividade eminentemente social. Quando perguntado sobre o que mais o alegra no hospital, Fred, de 5 anos, responde: "Quando a Luciana acorda e eu brinco com ela".

É através dos brinquedos que as crianças falam de seu sentimento de enfermidade, predominantemente referido à ameaça de desintegração física: "Os brinquedos tão quebrados (...) A casa desmorona (...) Tem que consertar os brinquedos" (Fred, 5 anos).

Pela capacidade de brincar pode-se avaliar um adulto no ambiente hospitalar: "Eu achei as enfermeiras legais, elas brincam comigo", conta-nos Juliana, de 9 anos. Pode-se também avaliar o próprio ambiente: "Aqui é legal que tem velotrama" (Mauro, 7 anos). Além disso, pode-se vê-los como brinquedos. Fred fala, referindo-se ao estetoscópio: "Tem um negócio aqui no pescoço do médico que ouve tudinho".

Brincar é uma forma de viver.

De ultrapassar os sentimentos mais dolorosos. De vencer a solidão e a saudade.

Mauro (7 anos) nos ensina: "Quando eu tô com saudade? Ah, eu fico brincando...".

\section{NOVOS OLHOS PARA O PEDIATRA}

"Não é isto que nos cansa, e sim o fato de termos de elevar-nos até alcançar o nível dos sentimentos das crianças. Elevar-nos, subir, ficar na ponta dos pés, estender a mão. Para não machucá-las" (Korczak, 1981).

A humanização do atendimento médico vem sendo objeto de muitos questionamentos, principalmente quando se considera a criança doente, já tão naturalmente frágil e vulnerável. Muitas 
propostas vêm sendo feitas para tornar a Pediatria menos dura, menos normativa e menos distante do ser da criança.

Tisza \& Richardson, em trabalho publicado em 1956, descrevem um tipo de experiência realizada em um hospital pediátrico de Boston, hoje já plenamente incorporada à rotina de atendimento. Contando com profissionais da área de Educação, a proposta consiste em oferecer à criança hospitalizada tempo e lugar para se distrair, experimentar, criar e se expressar, através de uma técnica não-diretiva.

Outros autores, como Plank (Oremland \& Oremland, 1973) e Robertson (Shaefer, 1979), utilizam técnicas psicoterapêuticas (histórias, desenhos, pinturas, trabalhos com argila e tantos outros recursos lúdicos) para ajudar a criança na elaboração de seu processo de enfermidade e de hospitalização.

Klinzing \& Klinzing (1977) são mais diretos e privilegiam a escolarização. Os referidos autores acreditam que esta não só favorece que a criança fique em dia com seus deveres escolares, mas também proporciona um fator de estabilidade em sua vida e uma expectativa positiva de cura e de retorno às atividades anteriores.

Decelle (1981), em Paris, criou a "Sala de Brincar" dentro do hospital com objetivos os mais variados: local de leitura, de assistir à televisão, de estudar ou, simplesmente, de brincar.

Finalmente, o Programa Mãe Participante, relatado por Jacob et al. (1983), vem sendo desenvolvido no Instituto da Criança, em São Paulo. Partindo dos primeiros estudos de Spitz sobre o hospitalismo, a equipe interdisciplinar se propôs a trazer a mãe da criança para acompanhá-la dentro do hospital por 24 horas diárias, realizando, com as crianças e suas famílias, atividades destinadas a minimizar os efeitos nocivos que a hospitalização acarreta sobre todos. Hoje, após a promulgação da nossa Constituição mais recente, ter a mãe como acompanhante passou a ser um direito da criança e do adolescente e uma obrigação dos hospitais pediátricos.

Estas propostas, em conjunto, na verdade, respondem à questão crucial levantada por uma abordagem mais integral da enfermidade na infância: existem outras necessidades na vida de uma criança hospitalizada, não-médicas, que devem ser atendidas com igual relevância. É a partir daí que Klinzing \& Klinzing (1977) denominam o conjunto das atividades descritas acima como Programas de Vida Infantil.

Mas será que isso importa em algo na convalescença da criança doente e em sua saúde futura? A prática médica precisa mesmo ser mudada?

Por tudo aquilo que ouvimos das crianças, assumimos a posição de que isso importa, e muito - assim como muita coisa deve ser transformada. Mas, para que a transformação objetiva da realidade médica aconteça, não bastam "brinquedos", "mães", "psicoterapeutas" ou "educadores" nas enfermarias pediátricas. É necessário que haja uma reformulação radical na atitude do médico diante do sujeito da enfermidade - no caso, a criança. Concordamos com Mello-Filho (1986) quando diz que é no interior "da relação médico-paciente que se trava a verdadeira batalha da Medicina".

A metodologia qualitativa, neste sentido, revela-se um instrumento de inigualável valor no redirecionamento da Pediatria, tornando-a mais humana e mais próxima da realidade global do enfermo-criança. Esta metodologia nos permite, em última instância, conhecer de um modo diferente e mais amplo; penetrar por detrás dos gestos, lapsos, olhares furtivos, sorrisos ou lágrimas contidas na criança; ler o que não pode ser dito; compreender as palavras silenciadas; inferir o conteúdo latente, "o sentido que se encontra em segundo plano" (Bardin, 1977), a interseção de dois planos: o dos processos sociais e o da subjetividade.

Para além das propostas objetivas — algumas já em prática — de humanização do atendimento à criança hospitalizada, acreditamos que é no exercício de "escuta" que nos faremos, como pediatras, mais humanos. É ouvindo a criança naquilo que ela necessita dizer, em sua própria linguagem, em seu peculiar modo de ver o mundo, que podemos tornar relação médico-paciente mais sadia, e trazer para a realidade médica outras questões - e novos olhares. 


\section{RESUMO}

OLIVEIRA, H. A Enfermidade Sob o Olhar da Criança Hospitalizada. Cad. Saúde Públ., Rio de Janeiro, 9 (3): 326-332, jul/set, 1993.

No presente estudo, partimos dos pressupostos de que existe uma dimensão vivencial da enfermidade na infância e de que a criança doente é capaz de falar sobre ela, de alguma forma. O nosso objetivo é conhecer suas representações da doença, do tratamento médico, da hospitalização e da equipe de saúde. Para isso, durante o mês de julho de 1990, foram entrevistadas 15 crianças entre 5 e 11 anos de idade, hospitalizadas em três hospitais pediátricos da cidade do Rio de Janeiro. Utilizamos a metodologia qualitativa como forma de análise do material coletado, segundo recomendações de Minayo (1988) e Bardin (1977).

Falando sobre sua doença, as crianças nos falam sobre a prática médica, a organização da família moderna e de si próprias, enquanto sujeitos do brincar.

Palavras-Chave: Hospitalização; Aspectos Psicossociais; Pediatria; Brincadeiras Infantis

\section{REFERÊNCIAS BIBLIOGRÁFICAS}

ARIÈS, P., 1981. História Social da Criança e da Família. Rio de Janeiro: Guanabara.

BADINTER, E., 1985. Um Amor Conquistado: 0 $M$ ito do Amor Materno. Rio de Janeiro: Nova Fronteira.

BARDIN, L., 1977. A nálise do Conteúdo. Lisboa: Ed. 70.

COSTA, J. F., 1983. Ordem M édica e Norma Familiar. Rio de Janeiro: Graal.

CHATEAU, J., 1987. O Jogo e a Criança. São Paulo: Summus.
DECELLE, D., 1981. La Vie de I'Enfant a I'Hospital. Paris: CCI.

ENTRALGO, P. L., 1976. Historia Universal de la Medicina. Madrid: Salvat.

FOUCAULT, M., 1980. O Nascimento da Clínica. Rio de Janeiro: Forense Universitária.

JACOB, C. M. A.; OSELKA, G. W.; PASTORINO, A. C.; PETLIK, M. E. I.; FERRARI, V. P. M.; ISHIDA, A. C. H.; PATRAO, M. C. L.; SAKATA, C. K. \& SIQUEIRA, L. F. B., 1989. Programa Mãe Participante - Relato de experiência em Enfermaria Geral. Jornal de Pediatria, 65: 165-168.

KLINZING, D. R. \& KLINZING, D. G., 1977. The Hospitalized Child Communication Techniques for Health Personnel. New Jersey: Prentice Hall.

KORCZAK, J., 1981. Quando Eu Voltar a Ser Criança. São Paulo: Summus.

MELLO-FILHO, J., 1986. Concepção Psicossomática: Visão A tual. Rio de Janeiro: Tempo Brasileiro.

MEAD, M. \& WOLFENSTEIN, M. 1955. Childhood in Contemporary Cultures. Chicago: The University of Chicago Press.

MINAYO, M. C. S., 1988. O Desafio do Conhecimento - M etodologia da Pesquisa Social (qualitativa) em Saúde. Tese de Doutorado, Rio de Janeiro: Escola Nacional de Saúde Pública, Fundação Oswaldo Cruz.

OREMLAND, E. K. \& OREMLAND, J. D., 1973. The Effects of Hospitalization on Children. Illinois: Charles Thomas Publishers.

ORLANDI, O., 1985. Teoria e Prática do A mor à Criança: Introdução à Pediatria Social no Brasil. Rio de Janeiro: Jorge Zahar.

RILKE, R. M., 1983. Poemas: As Elegias de Duino e Sonetos a Orfeu. Porto: O Oiro do Dia.

SHAEFER, C., 1979. The Therapeutic U se of Child Play. London: Aronson Jason.

TISZA, V. B. \& RICHARDSON, M., 1956. The integration of a mental health program and a child psychiatric unit into a pediatric hospital. Pediatrics, 17: 104-109. 